\title{
\begin{tabular}{l|l} 
Аскаров М. М. & Развитие исторических и антропологических знаний
\end{tabular} о Центрально-Азиатском регионе в Западной Европе и США
}

Ташкентский государственный университет востоковедения, ул. Шахрисабз, д. 25, г. Ташкент, 100060, Республика Узбекистан; mirzokhid.askarov90@ gmail.com

Аннотация. Усиление интеграционных процессов в мире, трансформация современной идентичности и риск потери «самости», а также снижение чувства единства в полиэтническом обществе - все это порождает необходимость научных исследований национальной идентичности. На сегодняшний день в мире функционируют несколько институтов и центров по исследованию идентичности узбеков и других народов Центральной Азии. Были исследованы вопросы религиозной (исламской) идентичности, гендерные взаимоотношения, культурное наследие, советская политика по отношению к местной культуре (REEI, IU Bloomington; IEAS, UC Berkeley; CEERES, UChicago (CША) и др.); вопросы изучения истории, археологии, этнологии, антропологии, лингвистики, миграционные процессы народов Средней Азии и Кавказа (RSAA, Cambridge; SOAS, ULondon; SSS, UManchester (Великобритания) и др.); вопросы узбекской идентичности и идентификации, исламской культуры и идентичности, святые места, теоретическая антропология (Max Planck ISA (Германия)); a также продолжают свои исследования некоторые центры в Европе (ESCAS, CASCA) и CША (CESS) и др. Вышеперечисленные научные проекты, которые направлены на исследование идентичности (национальной, этнической) узбеков, также показывают актуальность и востребованность темы в международном масштабе. Целью статьи является показать динамику развития этих знаний на Западе, акцентируя внимание на теме идентичности узбекского народа, дать краткую характеристику и обозначить особенности каждого периода.

Ключевые слова: узбекская идентичность; Средняя Азия; Центральная Азия; ориентализм; исследовательские центры; региональные исследования; догоняющая этнография

Для цитирования: Аскаров М. М. Развитие исторических и антропологических знаний о Центрально-Азиатском регионе в Западной Европе и США // Научный результат. Социальные и гуманитарные исследования. 2021. T. 7. № 2. C. 160-177. DOI: 10.18413/2408-932X-2021-7-2-0-15

\section{M. Askarov \\ Development of historical and anthropological knowledge about the Central Asian region in the Western Europe and USA}

Tashkent State University of Oriental Studies, 25 Shakhrisabz St., Tashkent, 100060, Republic of Uzbekistan; mirzokhid.askarov90@gmail.com

Abstract: Strengthening of integration processes in the world, transformation of modern identity and the risk of losing "self", as well as a decrease in the sense of unity in a multiethnic society - all this gives rise to the need for scientific research on 
the study of identity. Today in the world there are several institutes and centers for the study of the identity of Uzbeks and other peoples of Central Asia. The questions of religious (Islamic) identity, gender relations, cultural heritage, Soviet policy in relation to local culture (REEI, IU Bloomington; IEAS, UC Berkeley; CEERES, UChicago (USA), etc.); issues of studying history, archeology, ethnology, anthropology, linguistics, migration processes of the peoples of Central Asia and the Caucasus (RSAA, Cambridge; SOAS, ULondon; SSS, UManchester (Great Britain), etc.); issues of Uzbek identity and identification, Islamic culture and identity, holy places, theoretical anthropology (Max Planck ISA (Germany)); and also some centers in Europe (ESCAS, CASCA) and the USA (CESS), etc. continue their research. The above scientific projects, which are aimed at researching the (national, ethnic) identity of Uzbeks, also show the relevance and importance of this topic on an international scale. The purpose of this article is to show the dynamics of the development of this knowledge in the West and the United States, focusing especially on the identity of the Uzbek people. According to foreign studies of the identity of Central Asian peoples, the development of scientific knowledge in this direction is divided into several stages. The reference point of the "symbolic" beginning of the study of the studied topic is the end of World War II, since most of the Western grants for the study of the Muslim world (region) and its identity began in the post-war period. The study of each period has its own reason, purpose and objectives, subject and methodology, features and results. The article briefly reveals the nature and characteristics of each period. At the end of the article, we will try to give our reasoning and conclusions on the selected problem.

Key words: Uzbek identity; Central Asia; Central Asia; orientalism; research centers; regional studies; catch-up ethnography

For citation: Askarov M.M. (2021), "Development of historical and anthropological knowledge about the Central Asian region in the Western Europe and USA", Research Result. Social Studies and Humanities, 7 (2), 160-177, DOI: 10.18413/2408932X-2021-7-2-0-15

В настоящее время сеть исследовательских центров и институтов (scholarship and academia) по изучению идентичностей народов Средней Азии, в частности, Узбекистана, расширяется. Растет глубина и объем научных направлений данной тематики, совершенствуются методология и методы исследования, расширяется география исследований, что вызвано политическими, экономическими, социальными событиями современности. Большая часть публикаций издается на английском языке как языке международного научного сообщества. В ряде статей (Аскаров, 2019: 62-77; Аскаров, 2020: 239-250; Askarov, 2020) были проанализированы инструменты изучения узбекской идентичности, однако история развития этих знаний оста- лась не раскрытой. В данной статье анализируется формирование, динамика развития, цели и задачи исследований идентичностей Центрально-Азиатского региона зарубежными научными учреждениями.

География исследований идентичности центральноазиатских народов, в частности, узбеков. Известно, что исследование отдельного региона вне контекста его географической территории, границ с сопредельными странами и народами невозможно. Исходя из этого положения, Узбекистан всегда изучается неразрывно с Центральной Азией. Как справедливо отметила С. Горшенина, «до сих пор существует неразрешенная терминологическая путаница в наименовании "центрально-" 
или “среднеазиатского» региона. В этой связи научное определение границ термина остается размытым, что мешает признанию результатов научных исследований этого ареала» (Горшенина, 2016: 40). Если во времена колонизации Российской империей по преимуществу использовали административные термины (Туркестан, Русский Туркестан и т. п.), то в советский период, во время национальнополитического размежевания, закрепляется термин «Средняя Азия и Казахстан». С этого периода под термином «Средняя Азия» стали понимать четыре новых советских государства и весь Казахстан.

В западной науке также нет единого названия для региона. Если до 60-х годов $\mathrm{XX}$ века научные поиски подразделялись на изучение континентов (Азия, Африка, Латинская Америка), то после 60-х годов произошел переход на «региональные исследования» (area studies), которые были сосредоточены на изучении отдельных регионов и народов (русские, тюркские, иранские и др. народы) (см.: Горшенина, 2016: 46-47). В конце XX - начале XXI вв. в западной и американской научной среде широко и взаимозаменяемо использовались термины «Внутренняя Азия» и «Евразия», а также «Средняя Азия» и «Центральная Азия» как основной синоним всех других именований. Такая путаница в терминологии, в обозначении области исследования, отграничение региона от остального мира или расширение территории до «Большой Евразии» тормозит развитие научных исследований ${ }^{1}$.

Для западной и американской (West) науки все те территории, которые находились за пределами этих государств, обобщенно назывались не-западными (NonWest), или восточными (Orient), государствами. В период холодной войны Восток (Orient) также был известен как «третий

\footnotetext{
1 Проблема с названием и границами региона прослеживается в основном в зарубежных исследованиях. В трудах местных исследователей вопрос границ региона был рассмотрен и определен (см., напр.: Ходжаев, 2004).
}

мир» («третий мир» часто используется как синоним термина «Восток»), куда включались государства Азии и Африки (иногда Латинской Америки) (см.: Min Pun, 2019: 75-76).

Западные представления о Востоке называются «востоковедением» (Orientalism). Согласно Э. Саиду, «ориентализм - это стиль мышления, основанный на онтологическом и эпистемологическом различии, проводимом между "Востоком" и (в большинстве случаев) “Западом”» (Said, 2001). Исследования Центральной Азии, в частности Узбекистана и узбекской идентичности, также входили в состав регионального исследования Востока, и находились в центре внимания западных (в нашем случае британских, американских и некоторых европейских) исследований как части советского государства. Как полагает Э. Саид, существовали разные виды ориентализма, определяемые интересами таких метрополий, как Великобритания, Германия, Соединенные Штаты Америки, Россия, Франция и т. п. Хронологически в ориентализме преобладали последовательно ученые, обслуживавшие британский колониализм, затем исследователи Франции, после Второй мировой войны - США. В создании ориенталистских дискурсов о Востоке помимо этих трех стран важную роль играла также Германия.

Анализ показывает, что современные основные центры и институты по исследованию Центральной Азии (в частности Узбекистана) расположены в Великобритании, Германии, Российской Федерации, Франции, США, а также в некоторых азиатских государствах - Японии, Южной Корее. В данном исследовании термины «Центральная Азия» и «Средняя Азия» будут в дальнейшем носить равнозначный характер.

Согласно зарубежным исследованиям идентичности центральноазиатских народов, развитие научных знаний в этом направлении подразделяется на несколько этапов. Опорной точкой символического 
начала исследования изучаемой тематики является конец Второй мировой войны, так как большинство западных грантов на исследование мусульманского мира (региона), его идентичности начали выделять в послевоенный период. С этого времени в западной и американской науке наблюдаются следующие этапы изучения восточных идентичностей:

1. Колониальный период - с 50х годов до начала 90-х годов (подразделяется на два микроэтапа: 50-60-е годы и 7080-е годы) (Chari S. and Verdery K., 2009: 34; Liu, 2003; Liu, 2011: 115-131);

2. Постколониальный (postcolonial) (иногда постсоциалистический (post-sociaistic) (Marsden, 2012: 340-365; Liu, 2011: 116-117) период (подразделяется на два микроэтапа: 90-е годы и начало XXI века).

Исследования каждого из вышеуказанных периодов имеют свои особенности оснований, целей и задач, предмета и методологии, проведения и результатов. Ниже кратко охарактеризуем каждый период.

Колониальный период. Еще до окончания Второй мировой войны было очевидно, что союзнические отношения между СССР и западными державами - не более чем временные. Ялтинская конференция, разделившая Европу на советскую и американскую сферы влияния, объективно заложила основу периода конфронтационных международных отношений, получивших название холодной войны. Политические действия Советского Союза и его бывших союзников по антигитлеровской коалиции на международной арене указывали на то, что надежды на мирное долговременное сотрудничество СССР с Западной Европой и США скорее утопичны, чем реальны.

В это же время Ближний Восток, имеющий жизненно важное стратегическое значение ввиду наличия запасов углеводородов, стал главной ареной соперничества между Западом и Советским Союзом. Для британских и французских иссле- дователей в 50-е годы было важно изучение Центральной Азии при советской власти, чтобы оценить степень успеха советской политики и ее вероятное влияние на новые реформистские и левые правительства, сформированные на Ближнем Востоке и в Южной Азии. Можно сказать, что 1950-е годы стали рождением современных исследований в Центральной Азии. Однако правительства Великобритании и Франции после утраты контроля над восточными мусульманскими регионами переключили свое внимание на изучение других регионов, так как регион перестал представлять политический интерес для этих стран.

1960-е годы являются периодом появления первых стипендий и грантов США, впоследствии обеспечивших этой стране опережающее развитие исследований Центральной Азии. Американское востоковедение восприняло большинство европейских парадигм в изучении исламского мира, но самые глубокие следы здесь оставила британская научная традиция. На усиленное изучение Центральной Азии и Востока в целом оказала влияние и государственная политика США. В 1958 г. Конгресс США принял Закон об образовании в области национальной обороны (NDEA), предусматривавший крупномасштабное государственное финансирование высшего образования. Раздел VI Закона обеспечивал субсидирование программ изучения языков и регионов. Параграф «Краеведение» включал такие предметы, как афроамериканские и латиноамериканские исследования. Региональные изыскания, в свою очередь, послужили стимулом для изучения Ближнего Востока и исламских исследований в США (см.: Rafiq, 2020).

Среди представителей британской школы 50-60-х годов, которые писали об идентичностях в Центральной Азии, особенно выделяются Дж. Уилер (G.Wheeler), О. Кэроэ (O.Caroe), Г. Гибб (H.Gibb), В. Коларз (W.Kolarz); среди французских исследователей отмечают $\quad$ В. Монтела 
(V.Monteil), А. Беннигсена (A.Bennigsen), Э. Каррерд'Анкосс (Carrère d'Encausse), Ш. Лемерсье-Келькеже (LemercierQuelquejay); среди американских исследователей указываются Р. Пайпс (R.Pipes), Л. Крэдер (L.Krader), М. Рывкин (M.Rywkin), К. Роберт (K.Robert), Э. Бэкон (E.Bacon), Э. Оулворт (Е. Allworth) и др. В числе американских исследователей было много выходцев из Советского Союза, Британии или Германии, которые были приглашены или отобраны для работы в ведущих университетах США, например, Д. Синор (D.Sinor), Н. Поуп (N.Poup), Ю. Брегель (Yu.Bregel), Й. Шахт (J.Schaht), Б. Льюис (B.Lewis), Ф. Хитти (F.Hitti) и др. 1970-е и 80-е годы ознаменовались существенными сдвигами в масштабе исследований идентичности, повышении их значимости, а также в расширении географии исследования. После «периода застоя» в англо-американских исследованиях особенно популярным являлась тема местного ислама, так как исламская религия толковалась как некая угроза советскому государству. Появляется ряд публикаций о центральноазиатском исламе. Если проанализировать авторство этих публикаций, то можно обнаружить, что большинство из них имеют отношение к А. Беннигсену и его коллегам по данному вопросу (Bennigsen, 1971; 1972; 1975; 1977; 1978; Bennigsen, A. and Lemercier-Quelquejay, C., 1979; Bennigsen, A. and Wimbush, S. 1979; Bennigsen, A. and Broxup, M., 1982). Верно было подмечено Д. Ибаньез-Тирадо и М. Марсденом, что исследователей особенно интересовали вопросы выживания местной исламской религии в условиях социализма и коммунизма (см.: ИбаньезТирадо, Марсден, 2016: 52). Именно в этот период в научную терминологию изучения Средней Азии вошел термин «советский ислам» (Carrère d'Encausse, 1974: 12-20; Bennigsen A. and Wimbush S., 1985: 294), что является подтверждением повышенного интереса к данному вопросу в указанный период.
Как уже отмечалось, появляется новое поколение ученых, которое получало знания по ориенталистике в таких известных американских университетах, как Колумбийский, Принстонский, Вашингтонский, Индианский, Йельский, и у таких видных исследователей, как А. Беннигсен, Ю. Брегель, Д. Синор, Э. Оулворт и др. С 1980-х годов это новое поколение исследователей начало опровергать предыдущие представления о народах и идентичностях Центральной Азии. Ученые разделились на две группы. С одной стороны, это были бывшие государственные служащие, многие из которых принадлежали к колониальной администрации или занимали должности, связанные с Советским Союзом. К ним относятся Ч. Хостлер (C.Hostler), О. Кэроэ (O.Caroe), Р. Конквест (R.Conquest), Дж. Уиллер. Другое направление представляли эмигранты из Восточной Европы и СССР или их потомки, такие как М. Рывкин (M.Rywkin), Э. Каррерд’Анкосс (Carrère d'Encausse), В. Коларз (W.Kolarz), Т. РаковскаХармстон (T. Rakowska-Harmstone). В обе группы, являясь одновременно эмигрантами и бывшими государственными служащими, входили А. Беннигсен и Б. Хайит (см.: Myer, 2002: 207). Если в идейном направлении исследований первой группы превалировали политические дискурсы, то вторая группа старалась подчеркивать несправедливость по отношению к мусульманским идентичностям со стороны правительств соответствующих стран.

Основателем «американской» школы изучения Востока и мусульманских регионов является А. Беннигсен, который в последние годы жизни преподавал в Чикагском университете. Одним из последних его учеников считался С. Уимбуш. Колумбийский университет в США - еще один центр изучения Центральной Азии. Э. Оулворт и М. Рывкин получили докторские степени в Колумбии. Одновременно с ними в Колумбии также работал географ Льюис, писавший о демографии Центральной Азии. Самым авторитетным уче- 
ным парижской школы считали Дж. Уилера, который являлся постоянным лектором в Королевском центральноазиатском обществе.

На научное знание о мусульманских идентичностях конца 70-х - 80-х годов также повлияло исследование Э. Саида и его труд «Ориентализм» (Said, 1978). Ориентализм стал одним из ключевых направлений в постколониальных исследованиях, а также в области исследований гендерных проблем, восточных идентичностей и этнических исследований. По словам Б. Петрика, «Саид критикует оппозицию Восток - Запад или “Магриб - Машрик”, которая придает французскому и британскому колониальному доминированию видимость справедливости» (Петрик, 2016: 83).

Второй период - постколониальнылй (post-colonial) (иногда постсоциалистический (post-socialistic)). В предшествовавший период рассматриваемый регион называли «черная дыра Центральной Азии» (Mesbahi, 1994). Несомненно, распад СССР в 1991 г. явился неожиданностью для многих исследователей; они не предполагали такого быстрого развития событий, в результате которого в конце 1990-х годов многолетние барьеры для исследований, наконец, исчезли. Появилась возможность изучать реалии Центральной Азии изнутри, на основе полевых материалов.

Мы согласны с мнением М. Ривз о том, что «антропологи, обучавшиеся за пределами Советского Союза, начали писать диссертации на полевых материалах из Центральной Азии еще в середине 1980х гг., когда длительные этнографические исследования в этом регионе впервые стали возможны» (например, диссертация Шоберлайн-Энгеля (Schoeberlein-Engel, 1994)) (Рив3, 2014: 61). Внезапное открытие региона положило начало «догоняющей этнографии» (catch-up ethnography) (Liu, 2011: 116) в западной антропологии. Эта ситуация полностью характеризует первое поколение антропологов после рас- пада Советского государства, которые получили образование в западных университетах и в основном занимались антропологическими и этнологическими исследованиями в Центрально-Азиатском регионе.

Существует несколько обстоятельств, в силу которых Центральная Азия и ее идентичности в настоящее время превратились в столь важный этнографический регион.

Во-первых, эта территория часто теоретически мыслится как продолжение других регионов и традиций - рассматривается как нечто удивительно пластичное по сравнению с культурами других мест (см.: Alexander, 2015: 316-322).

Во-вторых, согласно формулировке Б. Петрика, «окончание холодной войны важное событие, которое требует анализа следующих циркуляций: людей - теперь можно не ограничиваться только миграциями; воображаемого - с учетом той роли, которую играет телевидение, кино, интернет; реального - товаров, денег и т. д.» (Петрик, 2016: 86).

В-третьих, словами этого же автора, «бесчисленные политологи, которые не являются специалистами по Центральной Азии, несколько иным образом монополизировали изучение региона и "импортируют" сюда количественные методы, которые использовали в других географических ареалах. В результате сосредоточенность на конфликтах и исламе уже привела к изобретению мифов» (Петрик, 2016: 86).

В-четвертых, западные социологи пытались на основе накопленного научного материала дать верный ответ на актуальный вопрос, куда хочет идти Центральная Азия - к западу за демократией или назад к социализму.

Ocновныле подходы. В начале 1990-х годов было модно писать об этническом национализме как подавляющем политическом императиве постсоветской эпохи (см.: Myer, 2002: 237). Частично это связано с более ранней концепцией СССР как «тюрьмы народов», с оценкой колониального характера Советского государства, в 
которой подчеркивалась несправедливость национального размежевания.

Можно согласиться и с утверждениями антропологов Д. Ибаньез-Тирадо и М. Марсдена о том, что в этот период, и даже в начале XXI века в академических текстах Центральная Азия рассматривалась как «чрезвычайно ясно выделенный, но малоизученный регион мира» и часто фигурировала как «периферия» социальных явлений, центры которых располагались в других регионах (ИбаньезТирадо Д. и Марсден М., 2016: 51).

Контент-анализ публикаций этого периода показывает, что постсоветские центральноазиатские исследования, как правило, основываются на идеологической платформе окончания холодной войны: исследователи рассматривают проблему особенностей перехода от государственного социализма к демократии и капитализму с позиций неолиберального триумфализма (см.: Liu, 2011: 117; Chari and Verdery, 2009: 6-34).

Предмет исторических и антропологических исследований. В исследованиях после 1990-х годов заметны существенные изменения не только в подходах, но и в предмете. Холодная война, несколько десятилетий определявшая цель и задачи исследований на Западе и в США, закончилась. Как отмечала А. Рафик, к 1996 году исследования регионов (area studies) подвергались нападкам с нескольких позиций; специалисты утверждали, что исследования регионов были изобретением холодной войны, отражали политические интересы США и европоцентристские предрассудки, и теперь, когда холодная война закончилась, исследования регионов потеряли обоснованность и ценность (см.: Rafiq, 2020).

После утраты актуальности региональных исследований появляется реальная возможность полевых исследований культуры (cultural studies) антропологами и, следовательно, происходит расширение круга тем и объектов антропологического исследования. Со второй половины 90-х годов увеличилось количество «чистых» антропологических исследований, начали глубоко изучаться местные идентичности (узбек, таджик, киргиз и др.), культура и социальные институты, например, махалля и ее место в обществе (Д. Абрамзон), вопросы культуры и воспроизведения идентичности (L. Adams, Sh. Akiner, T. Levin), экономические и социальные изменения (D. Kandiyoti), узбекская национальная, региональная, этническая идентичности (J.Schoeberlein-Engel, V. Korotoyeva E. Allworth, Sh. Akiner, Sh. Akbarzadeh), этнография узбекского колхоза и сельского хозяйства (R. Zanca, D. Abramson), антропология Центральной Азии в сравнении с другими регионами (D. Eikelman), ислам и религиозная идентичность (J. Gross, A. Khalid, D. Eikelman, M. Olcott, O. Ro'i, N. Shahrani), проблема нации и национализма (J. Critchlow, N. Lubin), вопросы создания государства и трансформаций (K. Davis, W. Fierman, M. Mandelbaum, M. Olcott), гендерные вопросы (N. Megoran, H. Fathi) и др. Можно сделать вывод: в 90-е годы в исторических и антропологических исследованиях в целом продолжали доминировать вопросы исламской идентичности и постсоветского национального строительства. Это еще раз доказывает, что и в этот период центральноазиатскими исследованиями продолжали интересоваться больше с политической точки зрения, чем с антропологической. Но уже к концу 90-х годов оба направления занимали почти равные позиции.

Мы согласны с мнением М. Ривз о том, что несмотря на вышеперечисленные исследования этнографические публикации по Центральной Азии в начале XXI века для англоязычной аудитории были минимальными (автор использует метафору пустыни) (см.: Рив3, 2014: 62). Оживление антропологического исследования Среднеазиатского региона происходило очень медленно и неравномерно. Всплеск исследований часто был результатом политической ситуации. Возможно, это было связано, во-первых, с событиями 
11 сентября 2001 года, которые вновь заставили США глубже заняться среднеазиатскими народами (см.: Hanson, 2004: 2021), во-вторых, ростом населения и миграционных процессов из ЦентральноАзиатского региона на Запад. Соответственно увеличилось и количество публикаций. Кроме того, растет приток исследователей из других областей науки, которые ранее не занимались антропологией; например, из политологии пришли Э. Щац (E. Schats), Дж. Хизершоу (J. Heathershaw), M. Фумагалли (M. Fumagalli); из географии: Р.Бичсел (R.Bichsel), Н. Мегорэн (N. Megoren); из социологии: Л. Адамс (L.Adams); из истории М. Камп (М.Kamp), A. Халид (A. Khalid) и др. Увеличивается количество междисциплинарных исследований. Вслед за антропологами данной территорией начали параллельно заниматься политологи, социологи, этнологи, историки. Предположительно, такая ситуация больше связана с размером исследуемого поля, которая характеризуется как «небольшая».

Если в первые 10-15 лет XXI века, как отметила атнрополог М. Ривз, «англоязычные центральноазиатские исследования переживают бум в хорошем смысле этого слова» (Рив3, 2014: 65-66), то последние пять-шесть лет не дают, на наш взгляд, оснований для позитивного прогноза масштабов антропологических исследований. Это связано, с одной стороны, с резким уменьшением финансирования в западных исследовательских центрах, а также с препятствиями полевым исследованиям в центральноазиатских государствах, с другой.

Методология антропологических исследований. С обретением независимости и пересмотром прежних ориентиров изменяется и методология исследований. Исследователи, работавшие в Центральной Азии в 90-е годы XX века, в основном, имели образование в области только российской или советской этнографии и знали только русский язык. Как пишет М. Ривз, начиная с 2000-х годов, в среднеазиатских регионах можно было встретить настоящих специалистов в области тюркских, персидских или исламских исследований (см.: Рив3, 2014: 65-66).

Кроме того, в методологии изучения идентичности народов происходит отказ от универсальных теорий и переход к одноразовым схемам, которые характерны только для определенных регионов. По словам А. Байбурина, «на смену интерпретативным исследовательским стратегиям приходят описательные. Но коль скоро акцент делается на описании, то происходит резкое расширение количества описываемых объектов» (Байбурин, 2004: 96-97).

Как пишет С. Соколовский, «в социальных и гуманитарных науках за последние четверть века прослеживается постепенная замена единиц фундаментального уровня наблюдения: обществ, культур, этносов - если брать традиции британской, американской и советской антропологии и этнографии, на новые объекты. Их главным параметром становится изменчивость и текучесть - социальность (sociality), инаковость (alterity, otherness), этничность (ethnicity)» (Соколовский, 2004: 84).

Антропологические исследования узбекской идентичности. Первое антропологическое исследование узбекской идентичности в отдельности - это докторская работа Шоберлайна-Энгеля (см.: Schoeberlein-Engel, 1994). С этого времени написано много, на разные темы, включая изучение проблемы локальной динамики власти и государственного строительства (Adams, 1999: 355-373; Pétric, 2006: 64-69; Rasanayagam, 2011; Тревизани, 2016); нации и национализма, национальной (узбекской) идентичности (Roy, 2000; Doi, 2002; Akbarzadeh, 2003; Edgar, 2004; Hirsch, 2005; Fierman, 2006: 98-116; Khalid, 2007; Ferrando, 2008; Fierman, 2009: 1207-1228; Megoran, 2011; Ferrando, 2011; Khalid, 2015; Laruelle, 2016); национальных меньшинств и их «адаптивных стратегий» (Liu, 2011); проблемы национальной памяти и конструирования культурной истории 
народа (Adams, 1999); этнической идентичности (Schoeberlein-Engel, 1994; Alexander, 2015); исследование рабочих, деревенских «элит» и дехканских хозяйств (Kamp, 2006; Rasanayagam, 2011; Zanca, 2011); вопросов постколониального и постсоциалистического состояния (Chari and Verdery, 2009: 6-34; Liu, 2011: 117118); гендерных вопросов (Lobacheva, 1997; Kamp, 2006; Edgar, 2006; Kandiyoti, 2007; Kamp, 2014); взаимоотношений ислама и государства, религиозной идентичности (Akiner, 1997: 362-398; Akbarzadeh, 1997a: 517-542; 1997b, 65-68; Esenova, 2002: 11-38; Abramson and Karimov, 2007: 319-338; Montgomery, 2007; Ferrando, 2008: 489-520; Rasanagayam, 2011; Ferrando, 2011: 39-52; Hierman, 2015: 519-539; Khalid, 2017: 1-5) и др. Периодически издаются коллективные и авторские монографии, специальные тематические выпуски журналов, посвященные этнографии, этнологии и антропологии Центральной Азии (Д. Кандиоти и Мандел, 1998; Дж. Расанаянгам, 2006; Сахадео и Занка,
2007; Рив3, 2011; Кирмсе, 2011; Монтгомери, 2013; Рив3, Дж. Расанаянгам и Бейер, 2014) (Рив3, 2016: 97-116).

Можно убедиться, что антропологические исследования Узбекистана, а в региональном смысле, Центральной Азии, в начале XXI века намного расширились, однако сегодня эта динамика снова идет на снижение. Согласно точному утверждению Т. Тревизани, «антропология Центральной Азии все еще занимает неуверенную и маргинальную позицию новичка в глобальных антропологических дискуссиях и борется за полноценное институциональное и интеллектуальное признание» (Тревизани, 2016: 122-123).

Динамику развития антропологических знаний о Центральной Азии, а также по узбекской идентичности, можно продемонстрировать линейным графиком (см. рис. 1). (По вертикали: количество исследовательских центров, институтов и журналов: 1 ед. графика соответствует 10 единицам подсчета.)

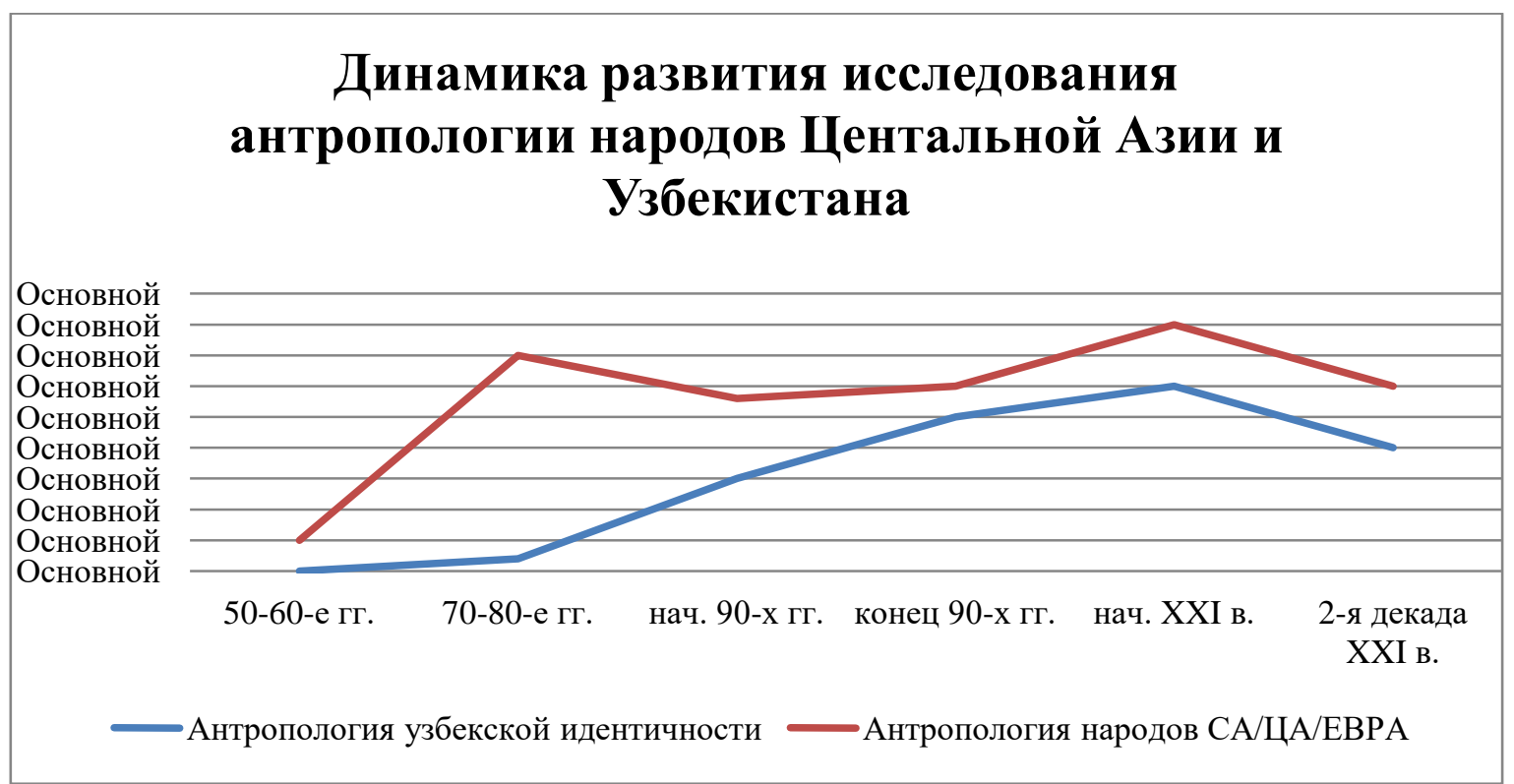

Рис. 1. Динамика развития исследований

Fig. 1. Research dynamics

Отправной точкой исследований условно считается завершение Второй мировой войны; началом изучения узбекской идентичности по полевым материалам условно считается начало 90-х годов.

Центры и институты по антропологическому исследованию народов Централь- 
ной Азии. Как уже отмечалось, контентанализ англо-американских исследований показывает, что в конце XX века центр исследований узбекской идентичности сместился из Западной Европы в США. В основном, это смещение обусловливается политическими интересами США, которые весьма активны в отношении мусульманских народов. Многие британские и французские центры просто прекратили свое существование или переориентировались на другие регионы, но несколько основных центров и институтов исследований именно узбекской идентичности продолжают свою деятельность и в этих странах.

Современные специалисты из Великобритании работают в Азиатском исследовательском центре, Российском и Евразийском исследовательском центре, Лондонской школе экономики, в университетах Лондона (SOAS) и Манчестера. Во Франции исследователей по изучению Центрально-Азиатского региона в основном обучают в Национальном институте восточных языков и цивилизаций (INALCO). Некоторые специалисты по региону проводят свои исследования в Центре тюркских, оттоманских, балканских и центральноазиатских исследований (CETOBAC), а также в Национальном центре научных исследований (Париж) и в университете Лозанны. В Германии проблемами идентичности узбеков и других народов Центральной Азии занимаются ученые в Институте социальной антропологии им. Макса Планка, в университете Тюбингена и в институте Азии и Африки Университета Гумбольдта.

В США основные центры и институты, выделяющие гранты по исследованию узбекской и других идентичностей региона, расположены в Центре российских, восточноевропейских и евразийских исследований (CREEES), университете Индианы в Блумингтоне - Российском и Восточноевропейском институте (REEI), Институте Центральной Азии и Кавказа, Центре восточноевропейских и российскоевразийских исследований при Чикагском университете (CEERES), а также в университетах в Вашингтоне, Принстоне и др.

Расширение географического масштаба исследований Центральной Азии связано с деятельностью таких организаций, как Общество центральноевразийских исследований (CESS), Европейская ассоциация среднеазиатских исследований (ESCAS) и Ассоциация славянских, восточно-европейских и евразийских исследований (ASEEES). В распространении знаний об идентичностях и культуре среднеазиатских народов важное место занимают такие журналы, как Central Asian Survey, Central Asian Affairs, Europe-Asia Studies, Ethnic and Racial Studies, Nationalities Papers, The Journal of Asian Studies, Journal of Contemporary Ethnography, Slavic Review, Journal of Islamic Studies, Anthropology \& Archeology of Eurasia и др.

Согласно результатам контентанализа, расширилось и концептуальное содержание исследовательского поля региона. Теперь исследования получают более глубокую проработку, привлекаются опытные специалисты, которые имеют достаточно знаний по антропологии и этнологии государств Средней Азии, вопросам гендера и ислама.

Как показывает наш анализ, рост этнографических и антропологических исследований по сравнению с 90-ми годами распределен неравномерно по государствам Центральной Азии. Если расположить пять постсоветских государств Центральной Азии по изученности региона, то на первом месте окажется Кыргызстан, который был более открыт для зарубежных антропологических исследований, на втором - Казахстан с факультетом антропологии, студенты которого прошли обучение в США, на третьем - Узбекистан со своими особенностями в развитии этнологической и антропологической науки, на четвертом - Таджикистан, который был недоступен во время гражданской войны, на пятом - Туркменистан с категорической недоступностью для этнографических исследований. 
Для вычисления примерного количества действующих исследовательских центров и институтов по изучению идентичностей народов Центральной Азии, а также расчета доли их участия в этом процессе была проанализирована деятельность этих организаций. Согласно полученным результатам, была составлена диаграмма (см. рис. 2).

\section{Доля исследовательских центров в изучении истории, этнологии, антропологии народов Центральной Азии}

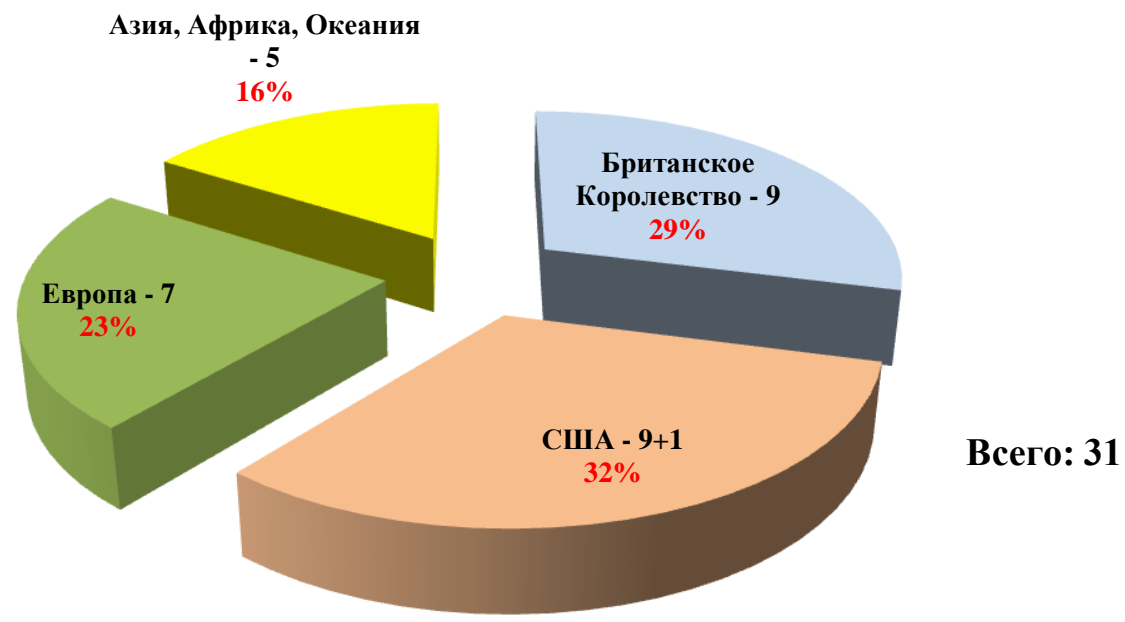

Рис. 2. Доля участия в изучении указанного региона

Fig. 2. Share of participation in the study of the specified region

На диаграмме представлена доля участия исследовательских центров и институтов в изучении народов Центральной Азии. Включение в список является личным субъективным выбором, для анализа были выбраны только самые известные и наиболее значимые центры и институты, причем акцент сделан в пользу тех институтов, где имеются исследования по этнологии, социальной и культурной антропологии, социологии и этнографии центральноазиатских народов.

Печатные и электронные публикации. Огромное влияние на развитие антропологической, этнологической, этнокультурной, политической, исторической науки оказывают периодические печатные и электронные издания. На основе контентанализа публикаций нами были выделены и классифицированы основные издательства, их печатные и электронные журналы, расположенные в Европе, США, в Азии (Евразии), Африке и Океании, составлена диаграмма, в которой можно увидеть долю участия издательств, в процессе распространения знаний по исследуемому региону (см. рис. 3).

Диаграмма показывает, что издательские дома Европы имеют больше печатных изданий, посвященных освещению именно этнологии, социальной и культурной антропологии Центрально-Азиатского региона. Однако стоит учитывать, что существенное количество этих публикаций приходится на долю издательских центров Великобритании. Если сравнивать количество публикаций только Великобритании и США, то разница будет небольшой. 


\section{Доля публикаций изданий по регионам}

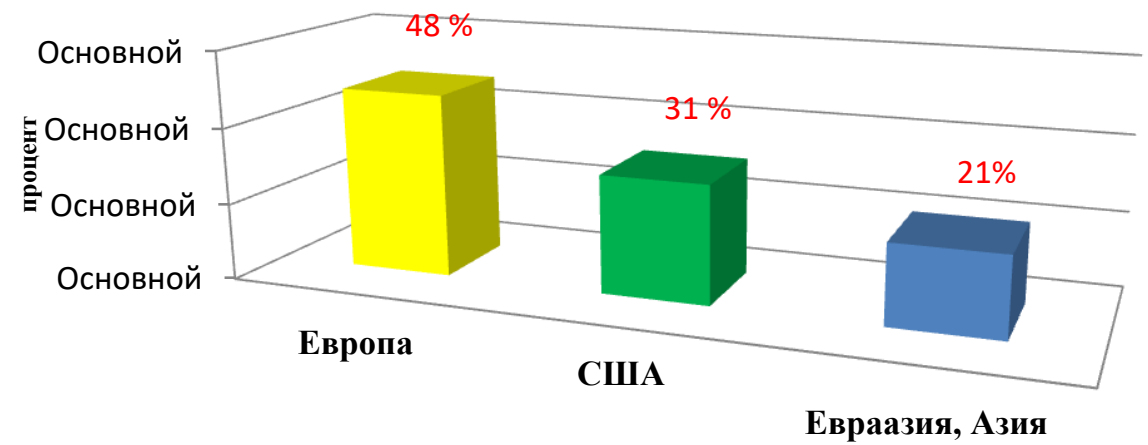

Рис. 3. Доля публикаций изданий по регионам

Fig. 3. Share of publications in editions by region

В заключение еще раз подчеркнем, что ввиду зависимости от геополитической ситуации исследование узбекской идентичности и идентичности всей Центральной Азии развивалось нестабильно. Развитие знаний о культуре и идентичностях среднеазиатских народов проходило неравномерно. Если в колониальный период вопрос рассматривался с позиции «региональных исследований», то после 1991 года ее сменяет «догоняющая этнография», которая в первую очередь направлена на изучение культуры. Первые исследования узбекской идентичности начались в конце 80-х годов, основные труды были написаны в конце 90-х и в начале нового тысячелетия.

Историографический анализ показывает наличие некоторых существенных внешних обстоятельств, таких как геополитика, период холодной войны, которые определяли ход исторической и антропологической науки до 90-х годов. После распада Советского государства геополитические влияния были заменены геостратегическими, которые нашли умеренное отражение в развитии исследований. Сфера основной профессиональной деятельности ученых также влияла на ход исследований. Если до 90-х годов большинство из них составляли бывшие военные и адми- нистративные работники, то с этого времени начали появляться настоящие антропологи и этнологи, что заметно отразилось на качестве материала.

Именно политическая составляющая во многом задавала темп, направление, предмет и методологию исследований: антропологическая наука была не свободна, часто эти антропологические исследования стремились к заранее предопределенному результату, даже еще не начавшись. Многие пробелы и проблемы в развитии этой области антропологических исследований в силу описанных исторических причин остаются не решенными и по сей день, требуют особого внимания научного сообщества.

\section{Литература}

Абашин, С.Н. От редколлегии // Антропологический форум, 2014. № 28, С. 137-140.

Аскаров, М. Анализ категорий идентичности в конце XX - начале XXI века на территории современного Узбекистана (на основе англоязычных материалов) // Научный результат. Социальные и гуманитарные исследования. 2019. T. 5 . № $4 . \quad$ С. 62-77. DOI: 10.18413/2408-932X-2019-5-4-0-6

Аскаров, М. Англоязычная антропология о природе узбекской идентичности в конце XIX - начале XX вв. // Вестник антропологии. 
$2020 . \quad$ № $1 . \quad$ (49). $\quad$ C. 239-250. $\quad$ DOI: 10.33876/2311-0546/2020-49-1/239-258

Байбурин, А. От редактора // Антропологический форум. 2004. № 1. С. 96-97.

Горшенина, С. «Средняя / Центральная Азия»: не более чем «этикетка» для сложного историко-культурного региона с меняющимися границами // Антропологический форум. 2016. № 28. С. 40-47.

Ибаньез-Тирадо, Д.,

Марсден, М. Антропологические исследования Центральной Азии в западной науке // Антропологический форум. 2016. № 28. С. 51-52.

Петрик, Б. Что такое «региональные исследования» в современной антропологии (на примере Центральной Азии) // Антропологический форум. 2016. № 28. С. 83-89.

Рив3, М. Антропология Средней Азии через десять лет после «состояния поля»: стакан наполовину полон или наполовину пуст? // Антропологический форум. 2014. № 20. С. 6166.

Ривз, М. След, траектория, точка давления: как переосмыслить «региональные исследования» в эпоху миграций // Антропологический форум. 2016. № 28. С. 97-116.

Смит, С. Современные тенденции в антропологических исследованиях // Антропологический форум. 2004. № 1. С. 77-78.

Соколовский, С. Принцип Гераклита (три гипотезы о причинах изменения традиций в антропологических исследованиях) // Антропологический форум. 2004. № 1. С. 84-85.

Тревизани, Т. По тонкому льду: значение и перспективы антропологии Центральной Азии // Атропологический форум. 2016. № 28. С. 122-125.

Ходжаев, А. Китайский фактор в Центральной Азии. Ташкент: Изд-во «Фан» Академии наук Республики Узбекистан, 2004. $136 \mathrm{c}$.

Abramson, D. and Karimov, E. Sacred Sites, Profane Ideologies: Religious Pilgrimage and the Uzbek State / in Sahadeo, J. \& Zanca, R. (eds) // Everyday Life in Central Asia: Past and Present. Bloomington: Indiana University Press, 2007. P. 319-338.

Adams, L. Celebrating independence: arts, institutions, and identity in Uzbekistan, Ph.D. dissertation, Sociology, University of California, Berkeley, 1999. 241 p.

Adams, L. Invention, institutionalization and renewal in Uzbekistan's national culture //
European journal of cultural studies. 1999. Vol. 2. № 3. P. 355-373.

Akbarzadeh, Sh. A note on shifting identities in the Ferghana valley // Central Asian Survey. 1997. Vol. 16. № 1. P. 65-68.

Akbarzadeh, Sh. The political shape of Central Asia // Central Asian Survey. 1997. Vol. 16. № 4. P. 517-542.

Akbarzadeh, Sh., Saeed, A. Islam and political legitimacy. London: Routledge Curzon, 2003. $200 \mathrm{p}$.

Akiner, Sh. Melting pot, salad bowl - cauldron? Manipulation and mobilization of ethnic and religious identities in Central Asia // Ethnic and Racial Studies. 1997. Vol. 20. № 2. P. 362398.

Alexander, C. The Anthropology of Central Asia // International Encyclopedia of the Social and Behavioral Sciences. 2015. Vol. 3, 2nd ed. Oxford: Elsevier. P. 316-322.

Askarov, M. Book review. Mongolia: a political history of the land and its people // Ethnic and Racial Studies. 2020. DOI: 10.1080/01419870.2020.1824002

Bennigsen, A. Islam in the Soviet Union: Religious and national problems // Religion and Atheism in the USSR and Eastern Europe. Ottawa: Carleton University Press, 1978.

Bennigsen, A. Islam in the Soviet Union: The religious factor and the nationality problem, in Bociurkiw, B. and Strong, J. (eds) // Religion and Atheism in the USSR and Eastern Europe. London: Macmillan, 1975.

Bennigsen, A. Islamic or local consciousness among Soviet Muslims, in Allworth, E. (ed.) // Soviet Nationality Problems. New York: Columbia University Press, 1971.

Bennigsen, A. Modernisation and conservatism in Soviet Islam, in Dunn, D. (ed.) // Religion and Modernization in the Soviet Union. Boulder, CO: Westview, 1977.

Bennigsen, A. The Muslims of European Russian and the Caucasus / in Vucinich, W. (ed.) // Russia and Asia: Essays on the influence of Russia on the Asian Peoples. Stanford, CA: Hoover Institute Press, 1972.

Bennigsen, A., Broxup, M. The Islamic Threat to the Soviet State. London: Croom Helm, 1982.

Bennigsen, A., Lemercier-Quelquejay, C. "Official" Islam in the Soviet Union, Religion in Communist Lands. 1979. Vol. 7, III. P. 148-159.

Bennigsen, A., Wimbush, S. Muslim National Communism in the Soviet Union: a Revolu- 
tionary Strategy for the Colonial World. Chicago: Chicago University Press, 1979.

Bennigsen, A., Wimbush, S. Muslims of the Soviet Empire. London: Hurst, 1985. 294 p.

Carrère d'Encausse, H. Islam in the Soviet Union: Attempts at Modernisation // Religion in Communist Lands. 1974. Vol. 2. № 4-5. P. 12-20.

Chari, S., Verdery, K. Thinking between the posts: postcolonialism, postsocialism, and ethnography after the Cold War, Comp. Stud. Soc. History. 2009. Vol. 51: 6. P. 6-34.

Doi, M.M. Gesture, Gender, Nation. Dance and Social Change in Uzbekistan, London: Bergin \& Garvey, 2002. 152 p.

Edgar, A. Bolshevism, Patriarchy, and the Nation: The Soviet "Emancipation" of Muslim Women in Pan-Islamic Perspective // Slavic Review, 2006. Vol. 65.

Edgar, A. Tribal Nation: The Making of Soviet Turkmenistan, Princeton, New Jersey: Princeton University Press, 2004. 320 p.

Esenova, S. Soviet Nationality, Identity, and Ethnicity in Central Asia: Historic Narratives and Kazakh Ethnic Identity // Journal of Muslim Minority Affairs. 2002. Vol. 22. № 1. P. 11-38.

Ferrando, O. Manipulating the Census: Ethnic Minorities in the Nationalizing States of Central Asia // Nationalities Papers. 2008. Vol. 36. № 3. P. 489-520.

Ferrando, O. Soviet population transfers and interethnic relations in Tajikistan: assessing the concept of ethnicity // Central Asian Survey. 2011. Vol. 30. № 1. P. 39-52.

Fierman, W. Identity, Symbolism, and the Politics of Language in Central Asia // EuropeAsia Studies. 2009. Vol. 61, № 7. P. 1207-1228.

Fierman, W. Language and education in post-Soviet Kazakhstan: Kazakh-medium instruction in urban schools // The Russian Review. 2006. Vol. 65(1). P. 98-116.

Fierman, W. On Uzbek "Nationalization" // Anthropology \& Archeology of Eurasia. 2004. Vol. 44: 4. P. 80-85.

Hanson, S. Central Asia and the Caucasus in the Contemporary Social Sciences, Social Science Research Council Items and Issues. 2004. Vol. 5. № 1-2. P. 20-21.

Hierman, B. Central Asian Ethnicity Compared: Evaluating the Contemporary Social Salience of Uzbek Identity in Kyrgyzstan and Tajikistan // Europe-Asia Studies. 2015. Vol. 67. № 4. P. 519-539.
Hirsch, F. Empire of Nations: Ethnographic Knowledge and the Making of the Soviet Union. Ithaca: Cornell University Press, 2005. 392 p.

Kamp, M. The new woman in Uzbekistan: Islam, modernity, and unveiling under communism. USA: University of Washington Press, 2006. 320 p.

Kamp, M. Women-initiated unveiling: state-led campaigns in Uzbekistan and Azerbaijan // Anti-veiling campaigns in the Muslim World / edited by S. Cronin. London and New York: Routledge, 2014.

Kandiyoti, D. The politics of gender and the Soviet paradox: neither colonized, nor modern? // Central Asian Survey, 2007. Vol. 26. № 4.

Khalid, A. Islam after Communism: Religion and Politics in Central Asia. Berkley: University of California Press, 2007. 253 p.

Khalid, A. Making Uzbekistan: nation, empire, and revolution in the early USSR. Ithaca and London: Cornell University Press, 2015. 444 p.

Khalid, A. The Roots of Uzbekistan: Nation making in the early Soviet Union // Uzbekistan: political order, societal changes, and cultural transformations / ed. by M. Laruelle. Washington, D.C.: The George Washington University, 2017. P. 1-5.

Laruelle, M. The Nation narrated: Uzbekistan's Political and cultural nationalism. London; New York, 2016.

Liu, M. Central Asia in the Post-Cold War World // Annual Review of Anthropology. 2011. Vol. 40. P. 115-131.

Liu, M. Detours from utopia on the Silk Road: ethical dilemmas of neoliberal triumphalism // Central Eurasian Studies Review. 2003. Vol. 2. № 2 .

Lobacheva, N. On the History of the Paranja // Anthropology \& Archeology of Eurasia. 1997. Vol. 36. № 2. P. 63-90.

Marsden, M. Southwest and Central Asia: Comparison, Integration or Beyond? / ed. by R. Fardon et al. // The SAGE Handbook of Social Anthropology, London: Sage, 2012. P. 340-365.

Megoran, N. Theorizing gender, ethnicity and the nation-state in Central Asia // Central Asian Survey. 2011. Vol. 18. № 1. P. 99-110.

Mesbahi, M. Central Asia and the Caucasus After the Soviet Union: Domestic and International Dynamics. Gainesville, FA: University of Florida Press, 1994.

Min Pun. The East-West Dichotomy: From Orientalism to Postcoloniality // IOSR Journal of 
Humanities and Social Science (IOSR-JHSS). 2019. Vol. 24. Issue 1. Ser. 8. P. 75-76.

Montgomery, D. Namaz, Wishing Trees, and Vodka: The Diversity of Everyday Religious Life in Central Asia / in Sahadeo J. \& Zanca R. (eds) // Everyday Life in Central Asia: Past and Present, Bloomington, IN: Indiana University Press, 2007. P. 355-370.

Myer, W. Islam and Colonialism: Western Perspectives on Soviet Asia, London-New York: Routledge \& Curzon, 2002. P. 207-237.

Pétric, B.-M. Uzbekistan Is Not a Society Based on the Ethnic Principle, But It Can Become That // Anthropology \& Archeology of Eurasia. 2006. Vol. 44. № 4. P. 64-69.

Rafiq, A. Orientalism and Western Academia [Электронный pecypc] URL: https://www.academia.edu/36621637/ORIENTAL ISM_AND_WESTERN_ACADEMIA (дата обращения: 02.08.20).

Rasanagayam, J. Islam in Post-Soviet Uzbekistan: The Morality of Experience. Cambridge University Press, 2011. 213 p.

Roy, O. The New Central Asia: The Creation of Nations, New York: New York University Press, 2000. 222 p.

Said, E. Orientalism. London and Henley: Routledge \& Kegan Paul, 1978. 368 p.

Said, E. Orientalism: Western Conceptions of the Orient. New Delhi: Penguin Books, 2001. $396 \mathrm{p}$.

Schoeberlein-Engel, J. Identity in Central Asia: Construction and Contention in the Conceptions of "Özbek", "Tâjik", "Muslim", "Samarqandi" and Other Groups, PhD diss., Harvard University Press, 1994.

Zanca, R. Life in a Muslim Uzbek Village: Cotton Farming After Communism, Wadsworth: Cengage Learning, 2011.212 p.

\section{References}

Abashin, S. N. (2014), "From editorial board", Antropologicheskiy forum [Anthropological forum], 28, 137-140 (in Russ.).

Abramson, D. and Karimov, E. (2007), "Sacred Sites, Profane Ideologies: Religious Pilgrimage and the Uzbek State", in Sahadeo, J. \& Zanca, R. (eds), Everyday Life in Central Asia: Past and Present, Indiana University Press, Bloomington, IN, 319-338.

Adams, L. (1999), "Celebrating independence: arts, institutions, and identity in Uzbeki- stan", Ph.D. Thesis, Sociology, University of California, Berkeley.

Adams, L. (1999), "Invention, institutionalization and renewal in Uzbekistan's national culture", European journal of cultural studies, 2 (3), 355-373.

Akbarzadeh, Sh. (1997), "The political shape of Central Asia", Central Asian Survey, 16, (4), 517-542. (a)

Akbarzadeh, Sh. (1997), "A note on shifting identities in the Ferghana valley", Central Asian Survey, 16 (1), 65-68. (b)

Akbarzadeh, Sh. and Saeed, A. (2003), Islam and political legitimacy, London: Routledge Curzon, UK.

Akiner, Sh. (1997), "Melting pot, salad bowl - cauldron? Manipulation and mobilization of ethnic and religious identities in Central Asia", Ethnic and Racial Studies, 20 (2), 362-398.

Alexander, C. (2015), "The Anthropology of Central Asia", International Encyclopedia of the Social and Behavioral Sciences, vol. 3, 2nd ed., Elsevier, Oxford, 316-322.

Askarov, M. (2020), "Book review. Mongolia: a political history of the land and its people", Ethnic and Racial Studies, DOI: 10.1080/01419870.2020.1824002.

Askarov, M. (2020), "English-speaking anthropology on the nature of Uzbek identity in the late 19th - early 20th centuries", Bulletin of Anthropology, 1 (49), DOI: $10.33876 / 2311-$ 0546/2020-49-1/239-258 (in Russ.).

Askarov, M. M. (2019), "Analysis of categories of identity in the late 20th - early 21 st centuries on the territory of modern Uzbekistan (based on English-language materials)", Research Result. Social Studies and Humanities, 5 (4), 6277, DOI: 10.18413/2408-932X-2019-5-4-0-6 (in Russ.).

Bayburin, A. (2004), "Editor's Note", Antropologicheskiy forum, 1, 96-97 (in Russ.).

Bennigsen, A. (1971), "Islamic or local consciousness among Soviet Muslims", in Allworth, E. (ed.), Soviet Nationality Problems, Columbia University Press, New York.

Bennigsen, A. (1972), "The Muslims of European Russian and the Caucasus", in Vucinich, W. (ed.), Russia and Asia: Essays on the influence of Russia on the Asian Peoples, Hoover Institute Press, Stanford, CA.

Bennigsen, A. (1975), "Islam in the Soviet Union: The religious factor and the nationality problem", in Bociurkiw, B. and Strong, J. (eds), 
Religion and Atheism in the USSR and Eastern Europe, Macmillan, London, UK.

Bennigsen, A. (1977), "Modernisation and conservatism in Soviet Islam", in Dunn, D. (ed.), Religion and Modernization in the Soviet Union, Westview, Boulder, CO.

Bennigsen, A. (1978), "Islam in the Soviet Union: Religious and national problems", Religion and Atheism in the USSR and Eastern Europe, Carleton University Press, Ottawa.

Bennigsen, A. and Broxup, M. (1982), The Islamic Threat to the Soviet State, Croom Helm, London, UK.

Bennigsen, A. and LemercierQuelquejay, C. (1979), "'Official' Islam in the Soviet Union", Religion in Communist Lands, 7 (III), 148-159. (a)

Bennigsen, A. and Wimbush, S. (1979), Muslim National Communism in the Soviet Union: a Revolutionary Strategy for the Colonial World, Chicago University Press, Chicago.

Bennigsen, A. and Wimbush, S. (1985), Muslims of the Soviet Empire, Hurst, London, UK.

Carrère d'Encausse, H. (1974), "Islam in the Soviet Union: Attempts at Modernisation", Religion in Communist Lands, 2 (4-5), 12-20.

Chari, S. and Verdery, K. (2009), "Thinking between the posts: postcolonialism, postsocialism, and ethnography after the Cold War", Comp. Stud. Soc. History, 51 (6), 6-34.

Doi, M. M. (2002), Gesture, Gender, Nation. Dance and Social Change in Uzbekistan, Bergin \& Garvey, London, UK.

Edgar, A. (2004), Tribal Nation: The Making of Soviet Turkmenistan, Princeton University Press, Princeton, NJ.

Edgar, A. (2006), "Bolshevism, Patriarchy, and the Nation: The Soviet 'Emancipation' of Muslim Women in Pan-Islamic Perspective", Slavic Review, 65.

Esenova, S. (2002), "Soviet Nationality, Identity, and Ethnicity in Central Asia: Historic Narratives and Kazakh Ethnic Identity", Journal of Muslim Minority Affairs, 22 (1), 11-38.

Ferrando, O. (2008), "Manipulating the Census: Ethnic Minorities in the Nationalizing States of Central Asia", Nationalities Papers, 36 (3), 489-520.

Ferrando, O. (2011), "Soviet population transfers and interethnic relations in Tajikistan: assessing the concept of ethnicity", Central Asian Survey, 30 (1), 39-52.

Fierman, W. (2004), “On Uzbek 'Nationalization", Anthropology \& Archeology of Eurasia, 44 (4), 80-85.

Fierman, W. (2006), "Language and education in post-Soviet Kazakhstan: Kazakh-medium instruction in urban schools", The Russian Review, 65 (1), 98-116.

Fierman, W. (2009) "Identity, Symbolism, and the Politics of Language in Central Asia", Europe-Asia Studies, 61 (7), 1207-1228.

Gorshenina, S. (2016), “Central Asia': No More Than a 'Label' for a Complex Historical and Cultural Region with Changing Borders", Antropologicheskiy forum [Anthropological forum], 28, 40-47 (in Russ.).

Hanson, S. (2004), "Central Asia and the Caucasus in the Contemporary Social Sciences", Social Science Research Council Items and Issues, 5 (1-2), 20-21.

Hierman, B. (2015), "Central Asian Ethnicity Compared: Evaluating the Contemporary Social Salience of Uzbek Identity in Kyrgyzstan and Tajikistan", Europe-Asia Studies, 67 (4), 519539.

Hirsch, F. (2005), Empire of Nations: Ethnographic Knowledge and the Making of the Soviet Union, Cornell University Press, Ithaca.

Iban'yez-Tirado, D. and Marsden, M. (2016), "Anthropological Studies of Central Asia in Western Science", Antropologicheskiy forum [Anthropological forum], 28, 51-52 (in Russ.).

Kamp, M. (2006), The new woman in Uzbekistan: Islam, modernity, and unveiling under communism, University of Washington Press, USA.

Kamp, M. (2014), "Women-initiated unveiling: state-led campaigns in Uzbekistan and Azerbaijan", Anti-veiling campaigns in the Muslim World, in Cronin, S. (ed.), Routledge, London and New York.

Kandiyoti, D. (2007), “The politics of gender and the Soviet paradox: neither colonized, nor modern?", Central Asian Survey, 26 (4).

Khalid, A. (2007), Islam after Communism: Religion and Politics in Central Asia, University of California Press, Berkley.

Khalid, A. (2015), Making Uzbekistan: nation, empire, and revolution in the early USSR, Cornell University Press, Ithaca and London, Greece and UK. 
Khalid, A. (2017), "The Roots of Uzbekistan: Nation making in the early Soviet Union", Uzbekistan: political order, societal changes, and cultural transformations, in Laruelle, M. (ed.), The George Washington University, Washington, D.C., 1-5.

Khodzhaev, A. (2004), Chinese factor in Central Asia. Publishing house "Fan" of the Academy of Sciences of the Republic of Uzbekistan, Tashkent, Uzbekistan (in Russ.).

Laruelle, M. (2016), The Nation narrated: Uzbekistan's Political and cultural nationalism, London; New York.

Liu, M. (2011), "Central Asia in the PostCold War World", Annual Review of Anthropology, 40, 115-131.

Liu, M. (2003), "Detours from utopia on the Silk Road: ethical dilemmas of neoliberal triumphalism", Central Eurasian Studies Review, $2(2)$.

Lobacheva, N. (1997), "On the History of the Paranja", Anthropology \& Archeology of Eurasia, 36, 2, 63-90.

Marsden, M. (2012), "Southwest and Central Asia: Comparison, Integration or Beyond?", The SAGE Handbook of Social Anthropology, in Fardon, R. et al. (eds), Sage, London, 340-365.

Megoran, N. (2011), "Theorizing gender, ethnicity and the nation-state in Central Asia", Central Asian Survey, 18 (1).

Mesbahi, M. (1994), Central Asia and the Caucasus After the Soviet Union: Domestic and International Dynamics, Gainesville, University of Florida Press, FA.

Min Pun (2019), "The East-West Dichotomy: From Orientalism to Postcoloniality", IOSR Journal of Humanities and Social Science (IOSRJHSS), 24 (1), ser. 8, 75-76.

Montgomery, D. (2007), "Namaz, Wishing Trees, and Vodka: The Diversity of Everyday Religious Life in Central Asia", in Sahadeo J. \& Zanca R. (eds), Everyday Life in Central Asia: Past and Present, Indiana University Press, Bloomington, IN.

Myer, W. (2002), Islam and Colonialism: Western Perspectives on Soviet Asia, Routledge \& Curzon, London-New York, 207-237.

Pétric, B.-M. (2006), "Uzbekistan Is Not a Society Based on the Ethnic Principle, But It Can Become That", Anthropology \& Archeology of Eurasia, 44 (4), 64-69.
Rafiq, A. Orientalism and Western Academia [Online], available at: https://www.academia.edu/36621637/ORIENTAL ISM_AND_WESTERN_ACADEMIA (Accessed 02 August 2020).

Rasanagayam, J. (2011), Islam in PostSoviet Uzbekistan: The Morality of Experience, Cambridge University Press, Cambridge.

Rivz, M. (2014), "Anthropology of Central Asia Ten Years After 'State of the Field': Is the Glass Half Full or Half Empty?", Antropologicheskiy forum, [Anthropological forum], 20, 6166 (in Russ.).

Rivz, M. (2016), “Track, trajectory, pressure point: how to rethink 'regional studies' in the age of migration" Antropologicheskiy forum [Anthropological forum], 28, 97-116 (in Russ.).

Roy, O. (2000), The New Central Asia: The Creation of Nations, New York University Press, New York.

Said, E. (1978), Orientalism, Routledge \& Kegan Paul, London and Henley.

Said, E. (2001), Orientalism: Western Conceptions of the Orient, Penguin Books, New Delhi.

Schoeberlein-Engel, J. (1994), "Identity in Central Asia: Construction and Contention in the Conceptions of 'Özbek', 'Tâjik', 'Muslim', 'Samarqandi' and Other Groups”, Ph.D. Thesis, Harvard University Press, Harvard.

Smit, S. (2004), Antropologicheskiy forum [Anthropological forum], 1, 77-78 (in Russ.).

Sokolovskiy, S. (2004), “The Heraclitus Principle (Three Hypotheses on the Causes of Changing Traditions in Anthropological Research)", Antropologicheskiy forum [Anthropological forum], 1, 84-85 (in Russ.).

Trevizani, T. (2016), "On Thin Ice: The Significance and Perspectives of Anthropology in Central Asia", Antropologicheskiy forum [Anthropological forum], 28, 122-125 (in Russ.).

Zanca, R. (2011), Life in a Muslim Uzbek Village: Cotton Farming After Communism, Cengage Learning, Wadsworth.

Информация о конфликте интересов: автор не имеет конфликта интересов для деклараиий.

Conflict of Interests: the author has no conflict of interests to declare. 


\section{ОБ АВТОРЕ:}

Аскаров Мирзохид Махаммаджсон угли, доктор философии (PhD) по историческим наукам, преподаватель кафедры истории народов Центральной Азии и этнологии, Ташкентский государственный университет востоковедения, ул. Шахрисабз, д. 25, г. Ташкент, 100060, Республика Узбекистан; mirzokhid.askarov90@gmail.com
ABOUT THE AUTHOR:

Mirzokhid M. Askarov, Doctor of Philosophy $(\mathrm{PhD})$ in Historical Sciences, Lecturer at the Department of History of the Peoples of Central Asia and Ethnology, Tashkent State University of Oriental Studies, 25 Shakhrisabz St., Tashkent, 100060, Republic of Uzbekistan; mirzokhid.askarov90@gmail.com 